\title{
Corrigendum
}

\section{Corrigendum to "Multifarious Beneficial Effect of Nonessential Amino Acid, Glycine: A Review"}

\author{
Meerza Abdul Razak, ${ }^{1}$ Pathan Shajahan Begum, ${ }^{2}$ Buddolla Viswanath (i), ${ }^{3}$ \\ and Senthilkumar Rajagopal ${ }^{1}{ }^{1}$ \\ ${ }^{1}$ Department of Biochemistry, Rayalaseema University, Kurnool 518002, India \\ ${ }^{2}$ Department of Zoology, K.V.R. Govt College for Women, Kurnool 518002, India \\ ${ }^{3}$ Department of Bionanotechnology, Gachon University, San 65, Bokjeong Dong, Sujeong Gu, Seongnam Si, \\ Gyeonggi Do 461 701, Republic of Korea
}

Correspondence should be addressed to Senthilkumar Rajagopal; senthilanal@yahoo.com

Received 2 February 2022; Accepted 2 February 2022; Published 23 February 2022

Copyright (C) 2022 Meerza Abdul Razak et al. This is an open access article distributed under the Creative Commons Attribution License, which permits unrestricted use, distribution, and reproduction in any medium, provided the original work is properly cited.

In the article titled "Multifarious Beneficial Effect of Nonessential Amino Acid, Glycine: A Review" [1], there was a typographical error in Section 3.2, where the word "heroin" should be corrected to "threonine."

\section{References}

[1] M. A. Razak, P. S. Begum, B. Viswanath, and S. Rajagopal, "Multifarious Beneficial Effect of Nonessential Amino Acid, Glycine: A Review," Oxidative Medicine and Cellular Longevity, vol. 2017, Article ID 1716701, 8 pages, 2017. 